\title{
HYPO PERFUSION MARKERS AS THERAPEUTIC AND PROGNOSTIC TOOLS FOR SEPTIC PATIENTS
}

\author{
Mohammed Abd EL-khalek Mohammed Ali, Noha Mohammed Elsharnouby, \\ Ibrahim Mamdouh Esmat, Milad Ragaey Zekry* and \\ Shirin Fekry Abd ElAzim Emara**
}

\author{
Department of Anesthesiology, \\ General Intensive Care and Pain \\ Management, Faculty of \\ Medicine - Ain Shams \\ University \\ ** Intensive Care Medicine, \\ MISR University for Science and \\ Technology \\ Cairo, Egypt
}

Corresponding :

Shirin Fekry Abd ElAzim Emara

Mobile: 01090020579

E mail:

Shirin_fekry@yahoo.com

Received: 9/1/2020

Accepted: 6/2/2020

Online ISSN: 2735-3540

\begin{abstract}
:
Background: Venous-to-arterial carbon dioxide difference ( $\mathrm{Pv}$ $\left.a \mathrm{CO}_{2}\right)$ and central venous oxygen saturation $\left(\mathrm{ScvO}_{2}\right)$ may reflect the adequacy of blood flow during septic shock states. We sought to test whether the development of $\mathrm{Pv}-\mathrm{aCO}{ }_{2}$ and $\mathrm{ScvO}_{2}$ during the early phases of resuscitation is related to multi-organ dysfunction and outcomes in a population of septic shock patients resuscitated targeting the usual oxygen-derived and hemodynamic parameters.
\end{abstract}

Aim of the Work: To assess the central venous-arterial carbon dioxide difference $\left(\mathrm{Pv}-\mathrm{aCO} \mathrm{C}_{2}\right)$ as a goal in goal directed therapy of sepsis resuscitation in comparison to central venous oxygen saturation $\left(\mathrm{ScvO}_{2}\right)$ and to test for their prognostic values.

Patients and Methods: This prospective observational study was performed in a 24-bed mixed ICU in a university-affiliated hospital. We examined all septic patients with a new episode admitted to the emergency room or proceeding from clinical wards during a 24month period. After approval by Ethical Medical Committee and obtaining informed consent, simultaneous blood samples were collected from the central venous line and the arterial catheter for obtaining venous and arterial gases respectively at (T0), and 6 hours (T6), 12 hours (T12) and 24 hours (T24) later. Patients were classified into four groups; two group (30patients) (A1 and A2) according to PcvO2 gap and another two groups (30patients) (B1 and B2) according to Central venous oxygen saturation. Group (A1) Decreasing Pcv-aCO2 (high at T0, declining at T6), Group (A2) Persistently high Pcv-aCO2 (high at T0 and T6), Group (B1) Increasing Central venous oxygen saturation (less than $70 \%$ at T0, increasing at T6), Group (B2) Decreasing Central venous oxygen saturation (less than 70\%at T0 and decreasing T6).

Results: Sixty-eight septic critically ill patients were included in this study. However; 8 patients were excluded from the study. Among the included patients in the study, 3 patients were excluded as they developed acute coronary syndrome, 4 patients refused to complete the treatment and discharged against medical advice, and 1 patient developed an ischemic cerebral vascular stroke. The final sample was therefore 60 patients. In this study, Central veno-arterial PCO2 gap and $\mathrm{ScvO} 2$ are considered as surrogate markers of the payment of the oxygen debt and early predictors of clinical outcome and organ dysfunction in the ICU. As regard the study, Central veno-arterial PCO2 gap is predictors for resuscitation in septic patients. As regard A Group, there was significant statistical difference between mortality and survival at T6, T12 and T24. However; regarding B Group, there was significant statistical difference between mortality and survival at 
T12 and T24. Also, this study shows that patients with persistently low $\mathrm{ScvO}_{2}$ are considered a good hypo perfusion marker for septic patients.

Conclusion: Data support the hypothesis that persistence of high $\mathrm{PCO}_{2}$ Gap and low $\mathrm{ScvO}_{2}$ during the resuscitation of septic patients is associated with significant higher multi-organ dysfunction and poor outcomes in critically-ill patients.

Recommendations: Future studies on a larger number of patients are needed and should test $\mathrm{PCO}_{2}$ Gap and $\mathrm{ScvO}_{2}$ as perfusion goals during early phases of the resuscitation of patients in septic shock to confirm its reliability.

Key words: Dysoxia - Septic Shock - Delta PCO2 Hemodynamics - Organ dysfunction - Clinical Outcome.

\section{INTRODUCTION:}

Human and animal models of early sepsis have repeatedly indicated that circulatory insufficiency results in an imbalance between systemic oxygen delivery and oxygen tissue demands. This may be due to decreased intravascular volume, loss of vasomotor tone, myocardial depression and increased metabolic demands ${ }^{(1)}$.

The inability to meet an increase in oxygen (O2) demand either by an increase in $\mathrm{O} 2$ delivery or an increase in $\mathrm{O} 2$ extraction can lead to tissue hypoxia ${ }^{(2)}$ An indicator of global tissue hypoxia is a key development preceding multi-organ failure and death ${ }^{(3)}$ Several markers of impaired tissue oxygenation have been explored to help identify patients at increased risk of complications or to be used as tools for direct treatment e.g. blood lactate level and central venous oxygen saturation ${ }^{(4)}$.

Increases in the venous to arterial $\mathrm{CO} 2$ difference $(\mathrm{Pv}-\mathrm{aCO} 2)$ which is known as co2 gap were reported during hypovolemic, cardiogenic, obstructive and septic shock. An inverse curvilinear relationship between $\mathrm{CO} 2$ gap and cardiac output was described, highlighting the importance of blood flow or venous $\mathrm{CO} 2$ accumulation and the importance of $\mathrm{CO} 2$ gap as a marker of global hypo perfusion during shock states ${ }^{(5)}$.
Early hemodynamic assessment of vital signs, central venous pressure and urine output fail to detect persistent global tissue hypoxia. A more selective resuscitation strategy include goal directed manipulation of cardiac preload, after load and contractility to reach to a balance state between oxygen delivery and oxygen demand $^{(3)}$.

The end points used to confirm such balance include normalized value for arterial lactate concentration, central venous oxygen saturation, base deficit and $\mathrm{PH}^{(6)}$. Lactate clearance and central venous oxygen saturation have been sufficiently used as goals for goal directed therapy for early sepsis $^{(7)}$.

\section{AIM OF THE WORK:}

The aim of the study is to assess the central venous-arterial carbon dioxide difference as a goal in goal directed therapy of sepsis resuscitation in comparison to central venous oxygen saturation and to test for their prognostic values.

\section{PATIENTS AND METHODS:}

This was a prospective randomized study that was conducted at the intensive care unit in Misr University for Science and Technology teaching hospital. 


\section{Study population:}

After obtaining approval by the institutional ethical medical committee and obtaining informed consent, 60 septic critically ill patients were included in this study.

\section{Exclusion criteria:}

The exclusion criteria were: patients who denied the consent, age less than 18 years, pregnancy, less than 24 hour admission in ICU, presence of an acute cerebral vascular event, acute coronary syndrome, acute pulmonary edema, primary diagnosis of cardiac dysrhythmia, contraindication for central venous catheter insertion, acute gastrointestinal bleeding, seizures, malignancy during chemotherapy and patients with advanced directives restricting implementation of the study protocol.

\section{Study design:}

This study was done after approval by Ethical Medical Committee and obtaining informed consent. A written informed consent was waived because no new therapeutic interventions were performed and all measurements and procedures routinely followed the local protocols for the management of septic patients. Simultaneous blood samples were collected from the central venous line and the arterial catheter for obtaining venous and arterial gases measurements respectively at T0, and 6 hours (T6), 12 hours (T12) and 24 hours (T24) later. APACHE II score was calculated in the first day. Sequential Organ Failure Assessment score (SOFA) was calculated from clinical and laboratory records daily and used to describe multiorgan dysfunction.

According to goal directed therapy, A 20 to $30 \mathrm{ml} / \mathrm{kg}$ body weight bolus of crystalloid was given every 30 minutes to achieve a central venous pressure of 8 to 12 $\mathrm{mm} \mathrm{Hg}$. If the mean arterial blood pressure is less than $65 \mathrm{~mm} \mathrm{Hg}$, vasopressors (norepinephrine) were given to maintain a mean arterial pressure of at least $65 \mathrm{~mm} \mathrm{Hg}$. If the hematocrit is less than 30 percent, red cells were transfused.

\section{Study groups:}

Patients were classified into four groups; two groups (30patients) (A1 and A2) according to PcvO2 gap and another two groups (30patients) (B1 and B2) according to Central venous oxygen saturation. Group (A1) Decreasing Pcv-aCO2 (high at T0, declining at T6), Group (A2) Persistently high Pcv-aCO2 (high at T0 and T6), Group (B1) Increasing Central venous oxygen saturation (less than $70 \%$ at T0, increasing at T6), Group (B2) Decreasing Central venous oxygen saturation (less than $70 \%$ at $\mathrm{T} 0$ and decreasingT6).

\section{Data analysis:}

Data were collected, revised, coded and entered to the Statistical Package for Social Science (IBM SPSS) version 23. The quantitative data were presented as mean, standard deviations and ranges when parametric, and presented as median with inter-quartile range (IQR) when non parametric. So, the p-value was considered significant as the following: P-value $>$ or $=$ 0.05: Non-significant (NS), P-value $<0.05$ : Significant (S), P-value $<0.01$ : Highly significant (HS).

\section{RESULTS:}

During the 24-month period, 68 septic critically ill patients were included in this study. However; 8 patients were excluded from the study. Among the included patients in the study, 3 patients were excluded as they developed acute coronary syndrome, 4 patients refused to complete the treatment and discharged against medical advice, and 1 patient developed an ischemic cerebral vascular stroke. Patients' characteristics of group A1 and A2 showed no statistically significant difference between the two groups regarding gender and age (Table 1). 
Table (1): Patient's characteristics of two group (A1\& A2):

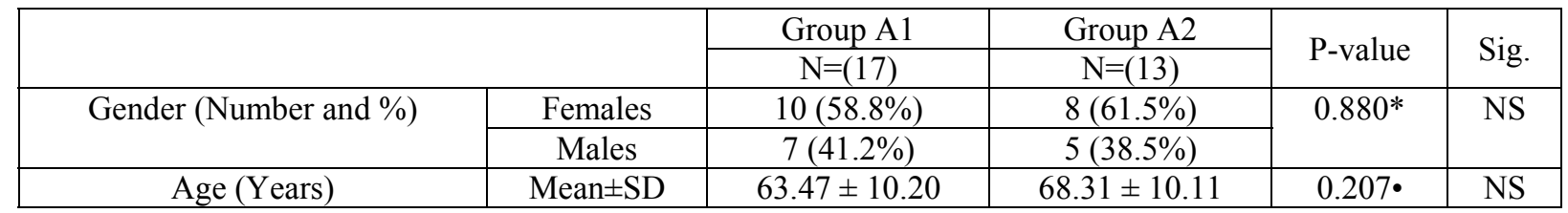

P-value $>0.05$ : Non significant (NS); P-value $<0.05$ : Significant (S); P-value $<0.01$ : highly significant (HS)

*:Chi-square test; $\bullet$ : Independent t-test

There was also, no statistically significant difference between groups (A1 \&

A2) regarding the need of inotropes and mechanical ventilation (Diagram 1).

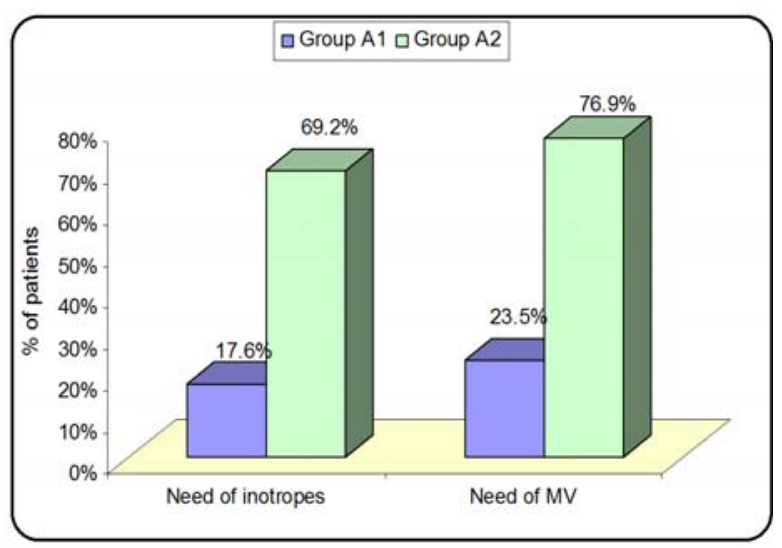

Diagram (1): Need of Inotropes and Mechanical ventilation in groups A1 \& A2

APACHE II Score in group A1 and group A2 showed statistically significance difference on the $1^{\text {st }}$ day being significantly lower in group A1 $\{22(17-30)\}$ than in group A2 $\{32(28-36)\}$
SOFA Score in group A1 and group A2 showed statistically significance difference on $2^{\text {nd }}$ and $3^{\text {rd }}$ day being significantly lower in group A1 $\{5(2-8), 4(2-7)\}$ than in group A1 $\{9(6-10), 8(6-12)\}$ respectively (Table 2$)$.

Table (2): APACHE II and SOFA Score distribution in groups A1 and A2:

\begin{tabular}{|c|c|c|c|c|c|}
\hline \multicolumn{2}{|c|}{} & Group A1 & Group A2 & P-value & Sig. \\
\cline { 3 - 6 } \multicolumn{2}{|c|}{} & Median (IQR) & Median (IQR) & & \\
\hline \multirow{2}{*}{ APACHE II Score (points) (First day) } & Median (IQR) & $22(17-30)$ & $32(28-36)$ & 0.012 & \multirow{2}{*}{ S } \\
\cline { 2 - 4 } & Range & $6-35$ & $16-36$ & & \\
\hline \multirow{2}{*}{ SOFA Score (points) (First day) } & Median (IQR) & $6(4-8)$ & $9(6-10)$ & 0.145 & NS \\
\cline { 2 - 4 } & Range & $2-12$ & $2-14$ & & \\
\hline \multirow{2}{*}{ SOFA Score (points) (Second day) } & Median (IQR) & $5(2-8)$ & $9(6-10)$ & 0.029 & S \\
\cline { 2 - 4 } & Range & $1-13$ & $3-14$ & & \\
\hline SOFA Score (points) (Third day) & Median (IQR) & $4(2-7)$ & $8(6-12)$ & \multirow{2}{*}{0.011} & S \\
\cline { 2 - 4 } & Range & $1-12$ & $3-16$ & & \\
\hline
\end{tabular}

P-value $>0.05$ : Non-significant (NS); P-value $<0.05$ : Significant (S); P-value $<0.01$ : highly significant (HS)

Mann Whitney test.

The number of organ dysfunction was significantly lower in group A1 $\{1(1-1)\}$ compared to group A2 $\{3(2-4)\}$ (Table 3 ).
The Intensive care length of stay was comparable between the two groups $\{6$ (6$11)\}$ in group $A 1$ and $7(5-10)$ in group $A 2$ 
(Table 3). However, mortality was compared to group A2 $\{9(69.2 \%)\}$ (Table significantly lower in group A1 $\{4(23.5 \%)\}$ $3)$.

Table (3): Number of Organ dysfunction, length of total stay and mortality in groups A1 and A2:

\begin{tabular}{|c|c|c|c|c|c|}
\hline \multicolumn{2}{|c|}{} & Group A1 N=(17) & Group A2 N=(13) & P-value & Sig. \\
\hline \multicolumn{2}{|c|}{ Mortality at 28 day (Number and \%) } & $4(23.5 \%)$ & $9(69.2 \%)$ & $0.012 *$ & S \\
\hline \multirow{2}{*}{ Length of ICU stay (Days) } & Median (IQR) & $6(6-11)$ & $7(5-10)$ & \multirow{2}{*}{$0.983 \%$} & NS \\
\cline { 2 - 5 } & Range & $3-17$ & $4-19$ & & \\
\hline \multirow{2}{*}{ Length of Hospital stay (Days) } & Median (IQR) & $3(2-4)$ & $4.5(3.5-5.5)$ & \multirow{2}{*}{$0.270 \%$} & NS \\
\cline { 2 - 5 } & Range & $2-6$ & $3-6$ & & \\
\hline \multirow{2}{*}{ Number of organ dysfunction } & Median (IQR) & $1(1-1)$ & $3(2-4)$ & $0.001 \%$ & HS \\
\cline { 2 - 4 } & Range & $0-2$ & $0-5$ & & \\
\hline
\end{tabular}

P-value $>0.05$ : Non-significant (NS); P-value $<0.05$ : Significant (S); P-value $<0.01$ : highly significant (HS)

*:Chi-square test; $\$$ : Mann Whitney test

Also for two groups (B1 and B2), there between the two groups regarding gender was no statistically significant difference and age (Table 4).

Table (4): Patients characteristics in group B1 and B2:

\begin{tabular}{|c|c|c|c|c|c|}
\hline \multicolumn{2}{|c|}{} & Group B1 & Group B2 & P-value & Sig. \\
\cline { 3 - 4 } & Ne(15) & $\mathrm{N}=(15)$ & & \\
\hline \multirow{2}{*}{ Gender (Number and \%) } & Females & $8(53.3 \%)$ & $8(53.3 \%)$ & $1.000^{*}$ & NS \\
\cline { 2 - 4 } & Males & $7(46.7 \%)$ & $7(46.7 \%)$ & & \\
\hline Age (Years) & Mean \pm SD & $62.20 \pm 12.35$ & $63.00 \pm 11.51$ & $0.856 \bullet$ & NS \\
\hline
\end{tabular}

P-value $>0.05$ : Non-significant (NS); P-value $<0.05$ : Significant (S); P-value $<0.01$ : highly significant (HS)

*:Chi-square test; $\bullet:$ Independent t-test

Groups B1 and B2 showed comparable significantly higher in group B2 (86.7\%) results in the need of inotropes. However, compared to group B1 (26.7\%) (Diagram 2). the need of mechanical ventilation was

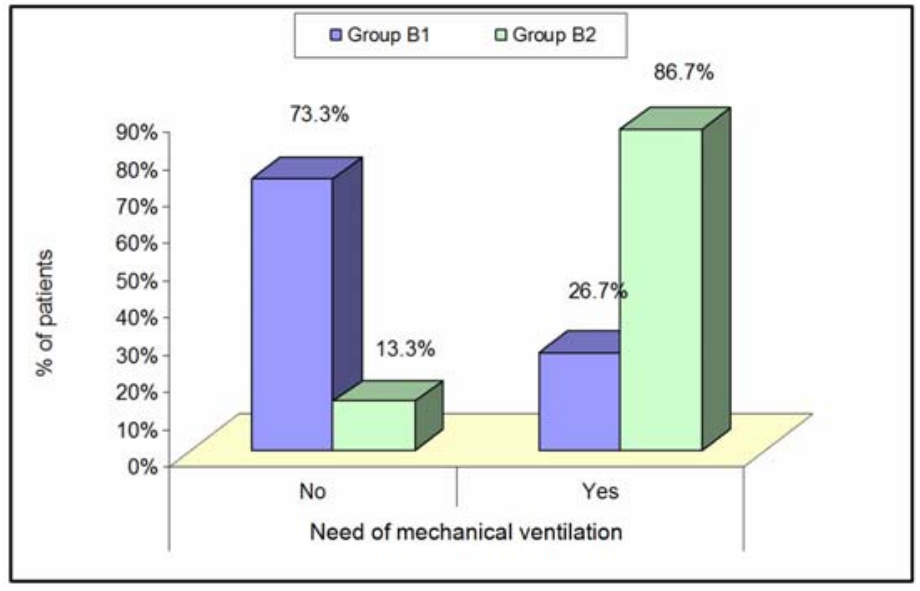

Diagram (2): Need of inotropes and need of mechanical ventilation in group B1 and B2.

The number of organ dysfunction was significantly lower in group B1 $\{5(33.3 \%)\}$ compared to group B2 $11(73.3 \%)$ (Table 5). The Intensive care length of stay was comparable between the two groups $\{6$ (5-
$10)\}$ in group B1 and $\{6(4-10)\}$ in group B2 (Table 6). However, mortality was significantly lower in group B1 $\{5(33.3 \%)\}$ compared to group B2 $\{11(73.3 \%)\}$ (Table $5)$. 
Table (5): Number of Organ dysfunction, length of total stay and mortality in group B1 and B2:

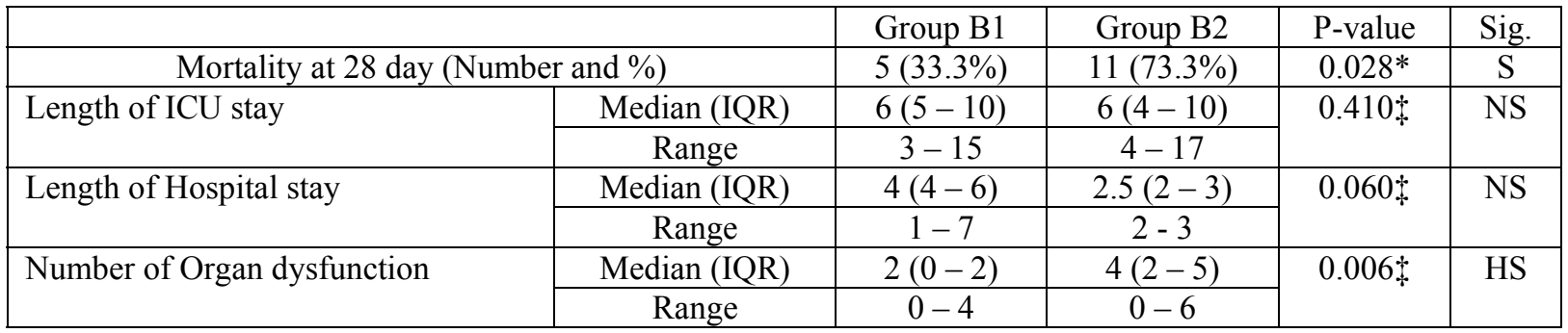

P-value $>0.05$ : Non-significant (NS); P-value $<0.05$ : Significant (S); P-value $<0.01$ : highly significant (HS) *:Chi-square test; $\$$ : Mann Whitney test.

APACHE II Score in group B1 and group B2 showed statistically significance difference on the $1^{\text {st }}$ day being significantly lower in group B1 $\{23(16-28)\}$ than in group B2 $\{34(22-36)\}$ (Table 6). SOFA statistically significance difference on $2^{\text {nd }}$ and $3^{\text {rd }}$ day being significantly lower in Subgroup B1 $\{4(3-8), 4(3-7)\}$ than in Subgroup B2 $\{9(3-11), 10(3-12)\}$ Score in group B1 and group B2 showed respectively (Table 6).

Table (6): Number of Organ dysfunction, length of stay and mortality in groups B1 and B2:

\begin{tabular}{|c|c|c|c|c|c|}
\hline & Group B1 & Group B2 & \multirow[t]{2}{*}{ P-value } & \multirow[t]{2}{*}{ Sig } \\
\hline & & Median (IQR) & Median (IQR) & & \\
\hline \multirow[t]{2}{*}{ APACHE II Score (Points) (First day) } & Median (IQR) & $23(16-28)$ & $34(22-36)$ & \multirow[t]{2}{*}{$0.017 \$$} & \multirow[t]{2}{*}{$\mathrm{S}$} \\
\hline & Range & $6-35$ & $17-46$ & & \\
\hline \multirow[t]{2}{*}{ SOFA Score (Points) (First day) } & Median (IQR) & $5(2-8)$ & $9(3-11)$ & \multirow[t]{2}{*}{$0.108 \ddagger$} & \multirow[t]{2}{*}{ NS } \\
\hline & Range & $2-11$ & $2-15$ & & \\
\hline \multirow[t]{2}{*}{ SOFA Score (Points) (Second day) } & Median (IQR) & $4(3-8)$ & $9(3-11)$ & \multirow[t]{2}{*}{$0.043 t$} & \multirow[t]{2}{*}{$\mathrm{S}$} \\
\hline & Range & $1-11$ & $2-16$ & & \\
\hline \multirow[t]{2}{*}{ SOFA Score (Points) (Third day) } & Median (IQR) & $4(3-7)$ & $10(3-12)$ & \multirow[t]{2}{*}{$0.033+$} & \multirow[t]{2}{*}{$\mathrm{S}$} \\
\hline & Range & $1-11$ & $1-17$ & & \\
\hline
\end{tabular}

P-value $>0.05$ : Non-significant (NS); P-value $<0.05$ : Significant (S); P-value $<0.01$ : highly significant (HS) \$: Mann Whitney test.

Pcv-aCO ${ }_{2}$ Gap had diagnostic T12 and T24 respectively and specificity performance in prediction of death, with sensitivity $92.31 \%, 84.62 \%, 76.92 \%$ at $\mathrm{T} 6$, $64.71 \%, 82.35 \%, 82.35$ at $\mathrm{T} 6, \mathrm{~T} 12$ and $\mathrm{T} 24$ respectively (Table7 and Diagram 3).

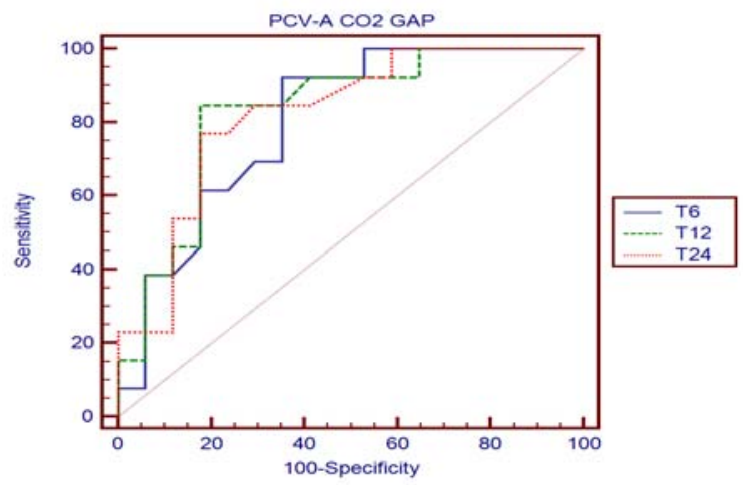

Diagram (3): Receiver operating characteristic curve (ROC) for Pcv-a $\mathrm{CO}_{2}$ Gap at T6, T12 and T24 as predictors for mortality. 
Table (7): Receiver operating characteristic curve (ROC) for Pcv-a $\mathrm{CO}_{2}$ Gap at T6 and T12and T24 as predictors for mortality:

\begin{tabular}{|c|c|c|c|c|c|c|}
\hline Pcv-a $\mathrm{CO}_{2}$ Gap & $\begin{array}{c}\text { Cut off } \\
\text { point }\end{array}$ & $\begin{array}{c}\text { Area } \\
\text { Under } \\
\text { Curve }\end{array}$ & Sensitivity & Specificity & $\begin{array}{c}\text { Positive Predictive } \\
\text { Value }\end{array}$ & $\begin{array}{c}\text { Negative Predictive } \\
\text { Value }\end{array}$ \\
\hline $\mathrm{T} 6$ & $>7$ & 0.801 & 92.31 & 64.71 & 66.7 & 91.7 \\
\hline $\mathrm{T} 12$ & $>6.5$ & 0.83 & 84.62 & 82.35 & 78.6 & 87.5 \\
\hline $\mathrm{T} 24$ & $>5.9$ & 0.821 & 76.92 & 82.35 & 76.9 & 82.4 \\
\hline
\end{tabular}

Central venous oxygen saturation had perfect diagnostic performance in prediction of death, with sensitivity $87.5 \%, 81.25 \%$ at $\mathrm{T} 12$,

T24 respectively and specificity $71.43 \%$, $71.43 \%$ at T12, T24 respectively (Table 8 and Diagram 4).

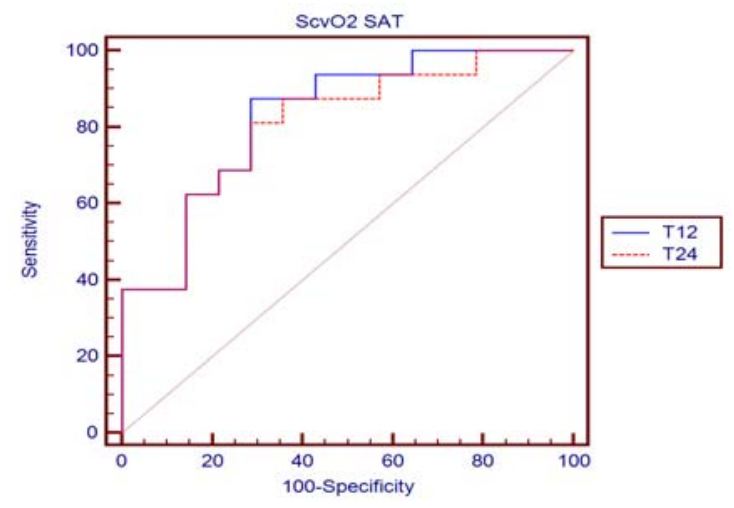

Diagram (4): Receiver operating characteristic curve (ROC) for central venous oxygen saturation at T12, T24 as predictors for mortality.

Table (8): Receiver operating characteristic curve (ROC) for central venous oxygen saturation at T12 and $\mathrm{T} 24$ as predictors for mortality:

\begin{tabular}{|c|c|c|c|c|c|c|}
\hline $\mathrm{ScvO}_{2}$ Saturation & Cut off point & Area Under Curve & Sensitivity & Specificity & $\begin{array}{c}\text { Positive } \\
\text { Predictive } \\
\text { Value }\end{array}$ & $\begin{array}{c}\text { Negative } \\
\text { Predictive } \\
\text { Value }\end{array}$ \\
\hline $\mathrm{T} 12$ & $\leq 70.9$ & 0.83 & 87.5 & 71.43 & 77.8 & 83.3 \\
\hline $\mathrm{T} 24$ & $\leq 71.6$ & 0.808 & 81.25 & 71.43 & 76.5 & 76.9 \\
\hline
\end{tabular}

\section{DISCUSSION:}

We studied a cohort of patients during the early phases of septic shock who were subjected to a comprehensive resuscitation aimed to target the usual hemodynamic and oxygen metabolism parameters. Patients were resuscitated immediately at (Time 0) and Patients were followed up by APACHE II score in the first day, SOFA score daily and 28 days mortality.

As regard the study, Central venoarterial $\mathrm{PcO}_{2}$ gap is superior to central venous oxygen saturation as a predictor for resuscitation in septic patients
As regard A Groups (A1 \& A2), there was significant statistical difference between mortality and survival at T6, T12 and T24. However; regarding B Groups (B1 and B2), there was significant statistical difference between mortality and survival at T12 and T24.

A study by Ospina and colleagues, who studied 108 patients with sepsis and septic shock, measured $\mathrm{Pcv}-\mathrm{aCO}_{2}$ gradient at time 0 and time 6 hours. They found that those with persistently high $\mathrm{Pcv}-\mathrm{aCO}_{2}$ gradient at T6 [7.0 (5.8 to 9.7)] developed more organ dysfunction assessed by SOFA score at day3 , than patients evolving with normal Pcv- 
$\mathrm{aCO} 2$ gradient during the first 6 hours of resuscitation [4.4 (2.7-5.4]. Additionally, they observed that persistently high Pcv$\mathrm{aCO}_{2}$ gradient was associated with a lower survival at day-28 (8). Similarly, Van Beest and colleagues studied 60 patients with septic shock. They measured Pcv-aCO2 gradient at time 0 and time 6 . They found a higher $\mathrm{Pcv}-\mathrm{aCO} 2$ gradient at Time 0 $(6.5 \pm 3.0$ vs. $3 \pm 1.8$,$) and Time 6$ ( $8 \pm 4$ vs. $3 \pm 2)$ in non survivors vs. survivors respectively (9). In contrary, Machado and colleagues disagree with a study done on 43 patients with severe sepsis and septic shock, who found that $\triangle \mathrm{PCO}_{2}$ and $\mathrm{SvcO}_{2}$ and its trends are unrelated to the SOFA score in first 24 hours ${ }^{(10)}$.

We observed that patients with persistently low $\mathrm{ScvO}_{2}$ are considered a good hypoperfusion marker for septic patients. Similarly, pope and his colleagues, who studied 619 patients who met criteria of sepsis and septic shock, showed that the mortality was $(40 \% ; 29-53 \%)$ where the $\mathrm{ScvO}_{2}$ measurement was still less than $70 \%$ after resuscitation ${ }^{(11)}$. Likely, Textoris and his colleagues, who studied 152 septic patients, found that $\mathrm{ScvO} 2$ below 70\% may be beneficial in detecting mortality ${ }^{(12)}$. Moreover, Mallat and his colleagues, who studied eighty patients with septic shock, found that Patients who reached a normal $\mathrm{PCO}_{2}$ gap at $\mathrm{T} 6$ had larger decreases in blood lactate concentration and Sequential Organ Failure Assessment scores (SOFA Score) on day one. The lactate decrease was greatest in the subgroup achieving both normal $\mathrm{ScvO}_{2}$ and $\mathrm{PCO}_{2}$ gap at T6. Lactate decrease, unlike $\mathrm{PCO}_{2}$ gap and $\mathrm{ScvO} 2$, was an independent predictor of 28-day mortality. Also found that Monitoring $\mathrm{PCO}_{2}$ may be a useful tool to assess the adequacy of tissue perfusion ${ }^{(13)}$. On other hand, Shin and his colleagues, found that $\mathrm{ScvO} 2$ has some limitations as a predictor for outcome and that $\mathrm{ScvO} 2$ has no further prognostic value after initial resuscitation. ${ }^{(14)}$

\section{Conclusion and Recommendations:}

The above data support the hypothesis that persistence of high $\mathrm{PCO}_{2}$ Gap and low $\mathrm{ScvO}_{2}$ during the early resuscitation of septic patients is associated with significant higher multi-organ dysfunction and poor outcomes in critically-ill patients.

Future studies on a larger number of patients are needed to test $\mathrm{PCO}_{2}$ Gap and $\mathrm{ScvO}_{2}$ as perfusion goals during early phases of the resuscitation of patients in septic shock to confirm their reliability.

\section{REFERENCES:}

1. Conti-Patara A, de AraujoCaldeira J, de Mattos-Junior E, et al. Changes in tissue perfusion parameters in dogs with severe sepsis/septic shock in response to goaldirected hemodynamic optimization at admission to ICU and the relation to outcome. J Vet EmergCrit Care (San Antonio) 2012; 22:409-18.

2. Vallet B and Futier E. Perioperative oxygen therapy and oxygen utilization. Curr Opin Crit Care 2010; 16:359-64.

3. Beal AL and Cerra FB. Multiple organ failure syndrome in the 1990s: Systemic Inflammatory Response and Organ Dysfunction. JAMA 1994; 271(3): 226-33.

4. Pearse R, Dawson D, Fawcett J, et al. Changes in central venous saturation after major surgery, and association with outcome. Crit Care 2010; 9:R694-9.

5. Mecher CE, Rackow EC, Astiz ME, et al. Venous hypercarbia associated with severe sepsis and systemic hypoperfusion. Crit Care Med 1990; 18:585-9.

6. Elliot D. An evaluation of the end points of resuscitation. J Am Col Sung 1998; 187:536-47.

7. Jones AE, Shapiro NI, Trzeciak S, et al. Lactate clearance vs central venous oxygen saturation as goals of early sepsis therapy: a randomized clinical trial. JAMA 2010; 303(8): 739-46. 
8. Ospina-Tascón GA, Bautista-Rincón DF, et al. Persistently high venous-to-arterial carbon dioxide differences during early resuscitation are associated with poor outcomes in septic shock. Critical Care. 2013; 17(6):R294.

9. van Beest PA, Lont MC, Holman ND, et al. Central venous-arterial $\mathrm{Pco}_{2}$ difference as a tool in resuscitation of septic patients. Intensive Care Med 2013; 39:1034-9.

10. Machado F, Guarnieri A, Freitas FG, et al. Prognostic value of central venous-arterial $\mathrm{PCO}_{2}$ difference in severe sepsis and septic shock patients. Critical Care. 2010; 14(1):P155.

11. Pope JV, Jones AE, Gaieski DF, et al. Multicenter study of central venous oxygen saturation $(\mathrm{ScvO}(2))$ as a predictor of mortality in patients with sepsis. Ann Emerg Med 2010; 55:40-6.
12. Textoris J, Fouché L, Wiramus $\mathrm{S}$, et al. High central venous oxygen saturation in the latter stages of septic shock is associated with increased mortality. Critical Care. 2011; 15(4):R176.

13. Mallat J, Lemyze M, Tronchon L, et al. Use of venous-to-arterial carbon dioxide tension difference to guide resuscitation therapy in septic shock. World Journal of Critical Care Medicine. 2016; 5(1):47.

14. Shin TG, Jo IJ, Hwang SY, et al. Comprehensive interpretation of central venous oxygen saturation and blood lactate levels during resuscitation of patients with severe sepsis and septic shock in the emergency department. Shock: Injury, Inflammation, and Sepsis: Laboratory and Clinical Approaches. 2016; 45(1):4-9. 


\author{
علامات نقص انسياب الام كأداة علاجية وتنبؤية لمرضي التسمم \\ محمد عبد الخالق محمد علي ، نهي محمد الشرنوبي، ابراهيم ممدوح عصمث، ميلاد رجائي ذكريث ،

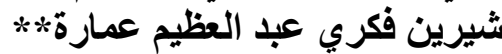 \\ * قسم التخدير الرعاية المركزة العامة و علاج الالم _كلية الطب - جامعة عين شمس

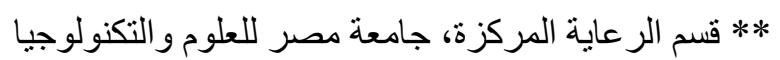

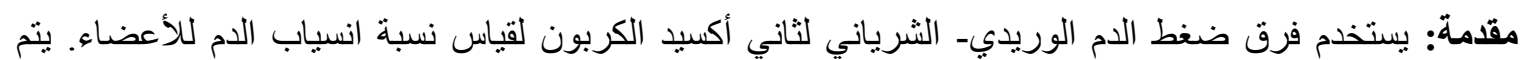

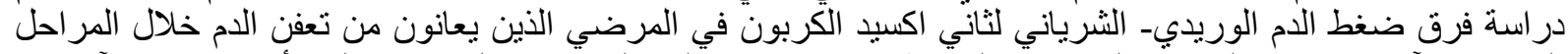

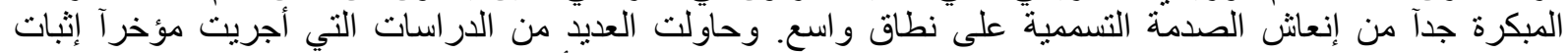

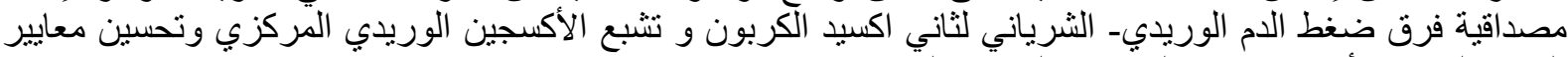

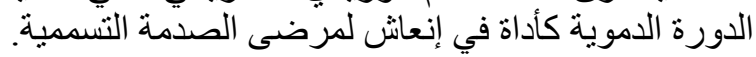

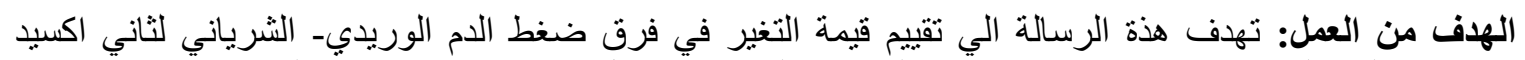

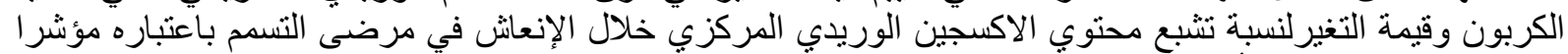

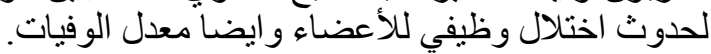

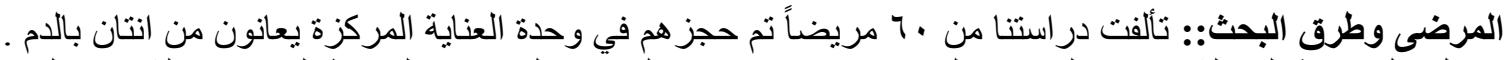

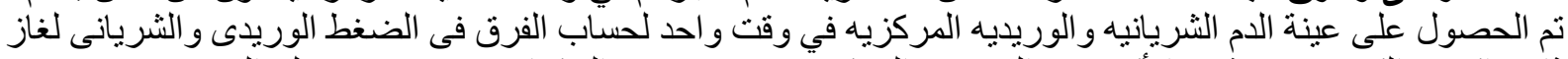
ثانى اكسيد الكربون، وتثبع الأكسجين الوريدي المركزي (ScvO2)

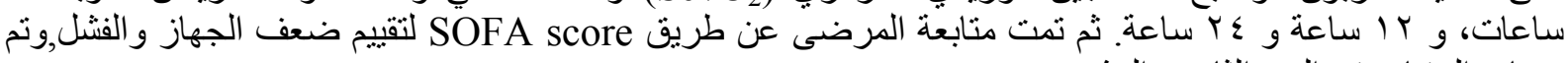
حساب الوفيات في اليوم الثامن و العشرين.

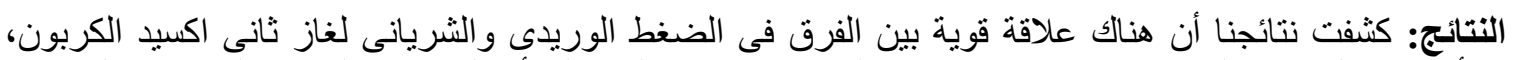

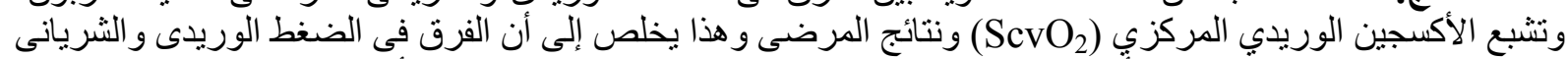

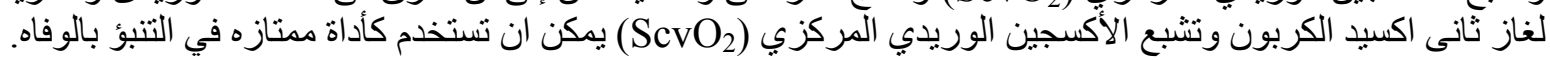

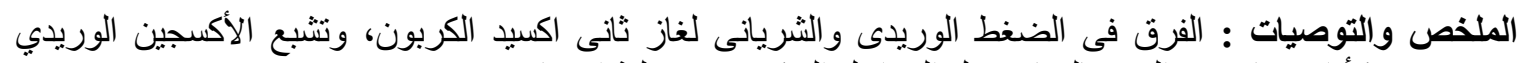

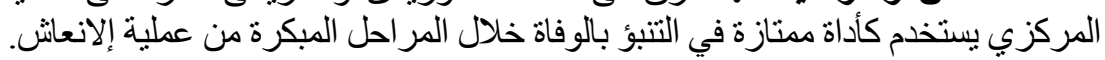

